\title{
The impact of chronic diseases on the health and well-being of South Africans in early and later old age
}

\author{
Margaret S. Westaway ${ }^{\mathrm{a}, \mathrm{b}, *}$ \\ ${ }^{a}$ Environment and Health Research Unit, Medical Research Council, Private Bag X385, Pretoria 0001, South Africa \\ ${ }^{\mathrm{b}}$ School of Health Systems and Public Health, Faculty of Health Sciences, University of Pretoria, P.O. Box 667, Pretoria 0001, South Africa
}

\section{A R T I C L E I N F O}

\section{Article history:}

Received 28 May 2008

Received in revised form 18 March 2009 Accepted 25 March 2009

\section{Keywords:}

Chronic diseases

Early and later old age

Health

Well-being

South Africans

\begin{abstract}
A B S T R A C T
This paper examines the impact of chronic disease status on health and well-being of South Africans in early and later old age. A structured questionnaire, comprising demographic characteristics, selfreported chronic disease status, an 18-item health problems scale and the health and well-being subscales from the SF-12 was used to collect data from 400 black, 101 Indian, 107 white and 102 colored residents of Greater Pretoria, South Africa. One hundred and ninety (27\%) reported no chronic disease, 181 (25\%) had hypertension alone, 179 (25\%) had hypertension combined with one or more other chronic diseases and 160 (23\%) had other chronic diseases without hypertension. There were no significant differences on health and well-being by race, language, gender or marital status. However, there were significant race, age group and gender effects on chronic disease status. Controlling for these factors, the no chronic disease group had significantly better health and well-being than the other three groups; the group with hypertension alone also had better health and well-being than the chronic disease groups with and without hypertension. It was concluded that chronic diseases combined with and without hypertension were more detrimental to health and well-being than no chronic disease or hypertension alone.
\end{abstract}

(c) 2009 Elsevier Ireland Ltd. All rights reserved.

\section{Introduction}

Chronic diseases are diseases of long duration and generally slow progression (World Health Organization, 2002). In 2002 (World Health Organization, 2002), there were an estimated 56 million deaths globally, of which $60 \%$ were due to the major chronic diseases (cardiovascular diseases, cancer, chronic respiratory diseases and diabetes mellitus) and accounted for $43 \%$ of the global burden of disease. By 2005, this estimate had increased by 2 million additional global deaths (Strong et al., 2005). Only 20\% of these deaths occurred in high-income countries, while $80 \%$ occurred in low-income and middle-income countries (Strong et al., 2005). In South Africa, the major causes of death in 2000 were chronic diseases (37\%), predominantly cardiovascular diseases; HIV/AIDS (30\%); the pre-transitional causes for communicable diseases, maternal conditions, peri-natal conditions and nutritional deficiencies (21\%); and injuries (12\%), revealing a quadruple burden of disease (Bradshaw et al., 2003).

\footnotetext{
* Correspondence address: Environment and Health Research Unit, Medical Research Council, Private Bag X385, Pretoria 0001, South Africa. Tel.: +27 12339 8537; fax: +27 123398594 .

E-mail address: Margaret.Westaway@mrc.ac.za.
}

Globally, the aging of populations is an underlying determinant of chronic diseases (Wang et al., 2005). South Africa has one of the most rapidly aging populations in Africa (May, 2002), with $7.3 \%$ of the population aged 60 and older in 2001 (Joubert and Bradshaw, 2004). Despite the impact of HIV/AIDS, this proportion is expected to increase to 9.5\% in 2015 (Joubert and Bradshaw, 2004), with a large majority of the country's population ( 4.5 million) being black aged 50 and older (Lehohla, 2006).

Concomitant with this South African aging profile is the increase in hypertension, overweight and obesity. Results from the 1998 South African Demographic and Health Survey revealed that hypertension was the most commonly reported chronic condition (Department of Health, 2001-2002). Twenty nine percent of men and $56 \%$ of women were overweight or obese (Department of Health, 2001-2002). White men were the most likely to be overweight or obese (57\%) and black men were the least likely (25\%). Among women, this pattern differed: with black women being the most likely to be overweight or obese (57\%).

Globally, co-morbidity is a common problem and increases with age. For example, someone can have hypertension and not have diabetes mellitus. On the other hand, someone with diabetes mellitus very often has hypertension. Co-morbidity is not only associated with the risk for major health-related outcomes, such as disability or mortality, but also with higher health care utilization

0167-4943/\$ - see front matter (c) 2009 Elsevier Ireland Ltd. All rights reserved. doi:10.1016/j.archger.2009.03.012 
and expenditure (Gijsen et al., 2001). Longitudinal studies suggest that the cumulative effect of co-morbidity is not simply additive. Certain combinations of diseases such as diabetes mellitus, hypertension or obesity have been found to be more detrimental to health outcomes than either one condition alone or in combination with other co-morbidities (Ettinger et al., 1994; Oldridge et al., 2001).

Previous South African research with black and white diabetic patients has provided support for the detrimental health and economic effects of co-morbidity (Westaway et al., 2003). In this study, over $60 \%$ of patients had hypertension, $80 \%$ of black and $87 \%$ of white patients were overweight or obese, $70 \%$ of black and $55 \%$ of white patients had poorly controlled blood pressure, and $63 \%$ of black and $39 \%$ of white patients had poor metabolic control (Westaway et al., 2003). These findings gave cause for concern, since poor management has significant health, well-being, health care utilization and economic implications for the long-term consequences of this chronic disease.

In the US, it has been reported that people with more education and income tend to have better health; men have slightly better well-being than women, older people have poorer health and wellbeing than younger people and African-Americans have poorer health, but not well-being, than Caucasian-Americans (Stewart et al., 1988). Patients with hypertension or diabetes mellitus were significantly more likely to rate their general health, but not their well-being, as poorer than people in the general population (Stewart et al., 1989). In South Africa, diabetic patients were significantly more likely $(p<0.01)$ to rate their health and well-being as poorer than people with no self-reported chronic diseases; diabetes mellitus, combined with hypertension, led to significant decrements in health and well-being (Westaway and Maluka, 2004).

Therefore, this paper focuses on the impact of chronic diseases in the lives of older South Africans to empirically increase the literature on the relationship between health and well-being, and improve health, well-being and management of chronic disease in primary health care settings. The objectives were to determine the impact of chronic diseases on health and well-being in early and later old age from a multi-racial perspective and provide assistance to health care workers in identifying those most at risk for poor health and well-being outcomes.

\section{Sample and methods}

\subsection{Sample}

A total of 710 respondents participated in the study: 400 black, 101 Indian, 107 white and 102 colored respondents. Participation rates varied across racial groups, since data collection for the black sample was completed in 2005 , whereas data collection for Indian, white and colored samples was only completed in July 2006. In addition, there were only 19 refusals among the black sample in comparison with twice that number for the Indian, white and colored samples. Therefore, 854 prospective respondents were approached for the current sample size of 710 .

Socio-demographic characteristics for the full sample are shown in Table 1. Ages ranged between 50 and 93 years (mean \pm S.D. $=69.7 \pm 9.7$ ). As expected, white respondents were significantly older than black, Indian and colored respondents $(p<0.001)$, since $33 \%$ of the White population were aged 50 or older in 2005 (Lehohla, 2006). There were 203 participants in the created near old age category (50-63 years), 250 in the old age category (64-73 years), 194 in the late old age category ( $74-83$ years), and 63 in the frail old age category (84+ years). The usual gender imbalance was found (Westaway and Gumede, 2001; Westaway, 2006; Westaway et al., 2007), with 497 women and 213 men participating in the study.
Table 1

Socio-demographic characteristics for the sample $(n=710)$.

\begin{tabular}{lrr}
\hline Socio-demographic characteristics & $n$ & $\%$ \\
\hline Age groups & & \\
Near old age (50-63 years) & 203 & 29 \\
Old age (64-73 years) & 250 & 35 \\
Late old age (74-83 years) & 194 & 27 \\
Frail old age (84+ years) & 63 & 9 \\
Gender & & 70 \\
Women & 497 & 30 \\
Men & 213 & \\
Schooling & & 33 \\
None & 84 & 39 \\
Primary & 235 & 16 \\
Lower secondary & 279 & \\
Upper secondary & 111 & 55 \\
Language & & 29 \\
African languages & 394 & 16 \\
Afrikaans & 204 & 31 \\
English & 112 & 16 \\
Employment status & & \\
Employed & 20 & \\
Pensioner & 574 & \\
Unemployed & 116 & \\
\hline
\end{tabular}

Education ranged between none and 12 years. In South Africa, 12 years of education encompasses primary and secondary schooling, but not tertiary education. White respondents had significantly more education than black, Indian or colored respondents $(p<0.001)$, indicative of restricted access to education for older black, Indian and colored South Africans. Only 72 participants had a post-high school academic qualification, predominantly a Nursing or Teaching Certificate. As expected, the major language for $88 \%$ of black respondents was Sepedi, Sesotho or Setswana (African languages); $98 \%$ of white and $94 \%$ of colored participants were Afrikaans-speaking; and 96\% of Indian participants spoke English. Only 20 respondents were working: 17 (8\%) of these were in the near old age category. Government pensions were the major source of income for 499 (70\%) and private pensions for 75 (11\%). Of those aged 64 and older, $84 \%$ were in receipt of a government pension. It would appear that the noncontributory government scheme is the major source of income in old age, late old age and frail old age.

The median household size was 5 (range: 1-15) for black respondents, 3 (range: $1-10$ ) for Indian respondents, 2 (range: $1-14$ ) for colored respondents and 1 (range: $1-2$ ) for white respondents. Fifty five percent of black respondents financially supported their families, with $83 \%$ dependent on a government pension or disability grant of between R780 and R820 ( \pm US\$ 116) per month. Black participants were more likely than Indian, colored and white participants to be living in an extended family situation, and take care of children and grandchildren $(p<0.001)$, a reflection of necessity. However, black respondents, who acted as caregivers, were equally likely to be unemployed as those without this responsibility $(p>0.05)$. White participants were more likely than black, Indian and colored participants $(p<0.001)$ to have lived in their current residence for a shorter period of time, indicative of the propensity for older white South Africans to move to smaller residences in early and later old age.

\subsection{Method}

Ethical approval for the study was obtained from the Faculty of Health Sciences Ethical Committee, University of Pretoria. Greater Pretoria community structures were consulted regarding the study. Written informed consent was obtained from all respondents who were willing to participate in the study. 
Different sampling points were used, due to difficulties in accessing respondents. Black, white, Indian and colored residents of Greater Pretoria, aged 50 and older, are more likely to live in the former Apartheid-restricted areas. Black and Indian residents tend to live in extended family situations, but for blacks this is an economic necessity, rather than the cultural factor of caring for older Indians. With the exception of Church groups, usually attended by only women, there are minimal social amenities, such as social clubs, senior citizen clubs, retirement centers and complexes in Pretoria's black townships. Due to the high crime rate, white, Indian and colored residents are barricaded in, many with guns and fierce dogs for additional protection. In our experience of fieldwork, it is dangerous for fieldworkers in these areas without making prior contact (Westaway, 2007). For the black sample, a simple random sample of 450 sampling points was drawn from a well-established black township in Greater Pretoria. For the Indian, colored and white samples, social clubs, senior citizen clubs, retirement centers and complexes acted as sampling points. As the majority of South Africa's population are black (Lehohla, 2006), proportional sampling was regarded as representative of Pretoria's racial composition.

Four multilingual fieldworkers were trained to administer the questionnaire. Particular attention during this training period was given to the consent form, in accordance with the World Association Declaration of Helsinki Ethical Principles for Medical Research involving Human Subjects. The questionnaire was not translated into Afrikaans or the nine recognized black languages, as the languages in Pretoria's black townships are not pure Sepedi, Sesotho or Setswana, but a mixture of Afrikaans, English, Sepedi and IsiZulu. In addition, the high rates of functional illiteracy among older black and colored South Africans, and a lack of questionnaire sophistication among blacks, Indians, coloreds and whites (Afrikaans-speaking), meant that translated self-report questionnaires would have little meaning to the majority of prospective respondents. During this training period, emphasis was placed on translating the essence of the questions, statements and phrases.

The fieldworkers used 450 sampling points as a starting point for data collection in the black township. Where the sampling point was a garage or shop, they went to the first available house on the right/left. Where no one was at home, refused to participate or under 50 years of age, the fieldworkers went to the next house on the right/left, until there was a willing participant. It was recognized that this process was likely to result in some nonresponse bias, in favor of caregivers rather than those in paid employment, but the high unemployment rate of 60\% (Westaway, 2006) among the black population suggested that this bias was not extreme. There were only 19 refusals, due to time constraints, indicating that black South Africans are very willing to participate in research activities.

For the Indian, colored and white samples, appointments were made at social clubs, senior citizen clubs, retirement centers and complexes to administer the questionnaire in the prospective respondents' own home or at these facilities. The questionnaire was administered during 2005/2006, due to the impossibility of conducting fieldwork in November, December and January. The fieldworkers only administered the questionnaire to respondents who were fully aware of their surroundings and had all their faculties.

A structured questionnaire (Appendix A), with a consent form, was designed to obtain information on: socio-demographic characteristics (age, gender, education, years of education, language, marital status and employment status), chronic disease status, number and type of health problems, health and well-being.

The health problems scale represents the perception of symptoms rather than the presence or absence of a definitive disease or disability (Macintyre et al., 1996; Macran et al., 1996). This 18-item experience of symptoms scale comprises: sleep problems, concentration difficulties, nervous problems, worrying over every little thing, always tired, headaches, constipation, fainting/dizziness, sickness/nausea, palpitations, back trouble, persistent cough, colds/flu, bladder/kidney problems, stiff/painful joints, sinus/catarrh/blocked nose, visual impairment, and hearing impairment (Macintyre et al., 1996; Macran et al., 1996). Responses are summed to provide an overall number of health problems (range: $0-18$ ).

Twelve items (Ware et al., 1996), from the SF-36 of the Rand Medical Outcomes Study, were used as a measure of health (Physical Component Summary) and well-being (Mental Component Summary). McHorney et al. (1993) conducted alpha factoring on the original SF-36 to determine whether physical and mental health items were the underlying dimensions of health-related quality of life. The first un-rotated component accounted for $55 \%$ of the variance, with loadings ranging between 0.67 and 0.82 . Principal components analysis revealed that there were distinctions between physical and mental health items (McHorney et al., 1993). The Physical Component Summary (PCS) and the Mental Component Summary (MCS) explained 90 and $94 \%$ of the variance in the SF-36, respectively (Ware et al., 1996), indicating that only 12 items were needed to assess health and well-being. Reliability (internal consistency) coefficients for South African diabetic patients (Westaway and Maluka, 2004) were 0.95 (PCS) and 0.88 (MCS). Test-retest reliability coefficients were 0.89 for PCS and 0.76 for MCS in the US (Ware et al., 1996).

The scoring system orients all items so that a higher score represents better health. For PCS, health rating is scored 5.0 (excellent), 4.4 (very good), 3.4 (good), 2.0 (fair) and 1.0 (poor). The two items measuring limitations in activities are scored from 0 (yes, limited a lot) to 2 (no, not limited at all). The two items measuring problems with work or activities are scored 0 (yes) and 1 (no). The pain item is scored from 5 (not at all) to 1 (extremely). For MCS, yes and no are scored 0 and 1 , respectively. All of the time is scored from 6 to 1 (none of the time) for calm and peaceful and the energy item, with reversed scoring on the downhearted and blue item. For the physical or emotional interference with social activities item, scoring is from 1 (all of the time) to 5 (none of the time). For PCS and MCS, scores are summed and transformed linearly from 0 to 100 , where 0 and 100 are assigned to the lowest and highest possible scores, respectively.

After data collection, four age groups were created: near old age (50-63 years), old age (64-73 years), late old age ( $74-83$ years) and frail old age (84+ years), in accordance with previous South African research (May, 2002). We asked black, white, Indian and colored (mixed race) South Africans in early and later old age to list their chronic conditions and then grouped them: Group 1 comprised persons reporting no chronic disease, Group 2 hypertension alone, Group 3 hypertension combined with one or more other chronic diseases that were mentioned (arthritis, diabetes mellitus, asthma, heart problems, a stroke, an ulcer, kidney failure, liver problems, epilepsy, and cancer), and Group 4 other chronic diseases without hypertension.

\subsection{Statistical analyses}

Alpha factoring was conducted on the 12-item health and wellbeing scale to ascertain a common factor model (Kim and Mueller, 1978). In alpha factoring, variables included in the factor analysis are considered a sample from the universe of variables, while assuming that these variables are observed over a given population, with a key emphasis on psychometric inference rather than statistical inference. Principal components analysis, followed by a two-factor orthogonal (VARIMAX) rotational solution, was used to 
ascertain the underlying dimensions of the SF-12. Only items with communality estimates (common factor variance) $>0.30$ were taken into consideration, as items with unique variance (specific variance + error variance) $>0.70$ tend to be unreliable (Child, 1970). In order to ascertain significant factor loadings at the $1 \%$ level, loadings $> \pm 0.50$ were examined (Child, 1970; Nunnally, 1978).

The reliability (internal consistency) of the health and wellbeing sub-scales was assessed (Cronbach, 1970); coefficient alpha of 0.70 was regarded as acceptable, between 0.71 and 0.80 as respectable, $>0.80$ as very good and $>0.90$ as excellent (Nunnally, 1978; Arias and de Vos, 1996; George and Mallery, 2003). Multitrait scaling was used to test item convergent and discriminant validity of the health and well-being sub-scales. This method tests whether each item in a hypothesized group is substantially related $(r>0.40)$ to a summation of the other items in the scale (Stewart et al., 1988). Fisher's $z$ test was used to compare the intercorrelation coefficients among items in the scale with coefficient alpha (item discriminant validity criterion), with the criterion of $z>1.96$ (Gaski and Nevin, 1985).

$T$ tests, Chi-squared tests, one-way analysis of variance (ANOVA), with Bonferroni adjustments for multiple comparisons, and Pearson product-moment correlation coefficients were used to determine demographic effects and relationships among the measures. Multiple analyses of co-variance were used to ascertain the effects of chronic disease status on health and well-being.

\section{Results}

\subsection{Chronic diseases}

Five hundred and eighteen respondents (73\%) reported one or more chronic diseases. Hypertension alone (25\%), followed by hypertension and diabetes mellitus (8\%), hypertension and arthritis (8\%), arthritis alone (8\%) and diabetes mellitus alone (5\%) were the most frequently mentioned chronic diseases. Previous South African research (Steyn et al., 2001; Department of Health, 2001-2002) has shown that $21 \%$ of adult South Africans, age-adjusted to the South African population, have hypertension, similar to current findings. However, the combination of hypertension with diabetes mellitus and arthritis would increase the prevalence of hypertension to $41 \%$, an identical prevalence rate to that found previously for South African women aged 55 and older (Department of Health, 2001-2002). The prevalence of diabetes mellitus also increased from 5 to $12 \%$ (blacks), 17\% (Indians) and $21 \%$ (coloreds), considerably higher than the prevalence rates reported previously for these populations (Department of Health, 2001-2002), but similar to rates in China and India (Reddy et al., 2005; Wang et al., 2005).

The four chronic disease categories consisted of: no chronic disease (27\%), hypertension alone (25\%), hypertension plus one or more other chronic diseases (25\%) and other chronic diseases without hypertension (23\%), representing a normal distribution. For black respondents, $30 \%$ had no chronic disease and $29 \%$ had hypertension alone, very similar to the $32 \%$ (no chronic disease) and 30\% (hypertension alone) for white respondents. For Indian respondents, 37\% had hypertension plus one or more other chronic diseases and 33\% had other chronic diseases without hypertension, identical to the $37 \%$ of colored respondents with hypertension combined with one or more other chronic diseases.

Indian respondents were the least likely to report no chronic disease $(p<0.001)$ than black, white and colored respondents. Age group and gender significantly affected chronic disease category $(p<0.001)$, with the old age (64-73 years) and late old age (74-83 years) groups being more affected by hypertension than the early and frail old age groups. Women were more likely than men
( $p=0.001$ ) to be affected by hypertension. These findings provided support for previous South African research on age and gender differentials in chronic disease reporting (Steyn et al., 2001; Department of Health, 2001-2002).

Sixty seven percent of black, $71 \%$ of Indian, $21 \%$ of white and $54 \%$ of colored respondents were reliant on the public health sector for their treatment. Only $10 \%$ of black, $6 \%$ of Indian and $6 \%$ of colored respondents, in comparison with $28 \%$ of white respondents, used private health care. The differences between public and private health care utilization were most likely due to a lack of access to medical insurance (Department of Health, 2001-2002).

\subsection{Health problems}

The most frequently reported health problems were: stiff or painful joints (56\%), visual impairments (47\%), back problems (44\%), worrying about every little thing (39\%) and sleeping problems (38\%), relating to three physical and two mental health problems (Macintyre et al., 1996; Macran et al., 1996). The average number of health problems was $4.8 \pm 3.3$ ), with $57 \%$ of the sample reporting four or more health problems. As expected, respondents with no chronic disease reported significantly less health problems than respondents in the other three chronic disease categories $(p<0.001)$, similar to findings from Sweden (Michelson et al., 2001). Respondents with hypertension alone had less health problems than respondents with hypertension and one or more other chronic diseases $(p=0.01)$, but not the other chronic disease group without hypertension $(p>0.05)$. Indian respondents had significantly more health problems than black, white or colored respondents $(p<0.001)$, corresponding to their chronic disease status. However, white and colored respondents reported significantly more health problems than black respondents $(p<0.001)$. These findings suggested that race and co-morbidity significantly affected experiences of illness (Ettinger et al., 1994; Michelson et al., 2001; Oldridge et al., 2001).

\subsection{Health and well-being}

The sample size of 710 fulfilled Nunnally's (1978) minimum criterion for factor analysis of the 12 -item scale (10 persons per item). Alpha factoring was conducted on the 12 items to ascertain a common factor model (Kim and Mueller, 1978). The first unrotated factor accounted for $65.6 \%$ of the variance, with high loadings, ranging between 0.74 and 0.85 , on each of the 12 items. These loadings corresponded to between 55 and $72 \%$ of the variance in the indicator being explained by the factor. The KaiserMeyer-Olkin measure of item sampling adequacy was 0.90 , in the "marvelous" category, according to Kaiser (1974). Bartlett's test of sphericity showed that the population matrix was not an identity (Chi-square $=10,641$, d.f. $=66, p<0.001$ ). Both tests confirmed that factor analysis was the correct procedure for the data.

Based on the Eigenvalues, the percentage of total variance accounted for by the factors and the scree plot, a two factor orthogonal (VARIMAX) rotational solution was conducted. All communality estimates exceeded the criterion of 0.30 (for reliable items) and ranged between 0.60 and 0.89 . The two factors explained $78.2 \%$ of the variance. Factor I contained seven significant loadings, accounting for $39.9 \%$ of the variance, and consisted of the six general health items and one item from the well-being health scale (how much of the time has your physical health or emotional problems interfered with your social activities). Factor II contained six significant loadings, accounting for $38.3 \%$ of the variance, and represented the six mental health items (Table 2).

Coefficient alpha was 0.91 for the general health and the mental health sub-scales, excellent reliability coefficients (Arias and de Vos, 1996; George and Mallery, 2003). The two factors were 
Table 2

Factor structure of the SF-12. ${ }^{\mathrm{a}}$.

\begin{tabular}{lll}
\hline Items & Factor I & Factor II \\
\hline General health & & \\
Health rating (excellent to poor) & $\mathbf{0 . 8 2}$ & 0.36 \\
Limitations in moderate activities & $\mathbf{0 . 8 8}$ & 0.24 \\
Limitations in climbing stairs & $\mathbf{0 . 8 8}$ & 0.27 \\
Accomplished less due to physical health & $\mathbf{0 . 7 2}$ & 0.44 \\
Limitations in work and other activities & $\mathbf{0 . 7 5}$ & 0.42 \\
Degree of pain interference with health & $\mathbf{0 . 7 4}$ & 0.43 \\
Well-being & & \\
Accomplished less due to emotional problems & 0.37 & $\mathbf{0 . 7 7}$ \\
Did not do other activities as carefully as usual & 0.37 & $\mathbf{0 . 7 9}$ \\
Felt calm and peaceful & 0.35 & $\mathbf{0 . 8 7}$ \\
Had a lot of energy & 0.36 & $\mathbf{0 . 8 7}$ \\
Felt downhearted and blue & 0.29 & $\mathbf{0 . 8 9}$ \\
Physical or emotional interference of social life & $\mathbf{0 . 5 7}$ & $\mathbf{0 . 5 2}$ \\
\hline a Loadings $>$ 0.50 in bold & &
\end{tabular}

a Loadings $>0.50$ in bold.

significantly related to each other $(r=0.70, p<0.001)$. However, this relationship was significantly lower $(z=12.4, p<0.001)$ than the square root of the product of their reliability coefficients. The unique variance in each of the two sub-scales provided support for discriminant validity (Gaski and Nevin, 1985). For general health, corrected item-total correlation coefficients ranged between 0.78 and 0.86; for well-being, these correlation coefficients ranged between 0.66 and 0.93. All correlations exceeded the item convergent validity criterion of $>0.40$ (Stewart et al., 1988).

The average score on the health sub-scale was $55.7 \pm 30.0$ and $71.5 \pm 27.6$ on the well-being sub-scale, higher than those reported previously (Ware et al., 1996), where scores ranged between 36.3 and 49.3 (health) and 37.0 and 53.8 (well-being). The full range of scores was observed for both measures. However, well-being was more negatively skewed than general health, indicating that the majority of respondents reported better well-being than general health. There were no significant differences on health and well-being by race, language, gender or marital status $(p>0.05)$. Significant, but extremely modest, negative correlations were found between age and health $(r=-0.12, p=0.002)$ and well-being $(r=-0.08, p=0.04)$, indicative of slightly poorer health and well-being for older respondents. Stronger negative correlations were found between number of health problems and general health $(r=-0.44, p<0.001)$ and well-being $(r=-0.40, p<0.001)$, suggesting that physical and mental health problems negatively affect health and well-being (Michelson et al., 2001).

\subsection{The effects of chronic disease status on health and well-being}

As there were significant racial, age group and gender differences on chronic disease status, multiple analyses of covariance (MANCOVAs), controlling for race, age group and gender, were used to investigate the effects of chronic disease on health and well-being. Estimated means showed that respondents with no chronic diseases had significantly better health $(m=69.4)$ and well-being ( $m=80.9)$ than those with hypertension alone (health: $m=57.3, p<0.001$; well-being: $m=73.4, p=0.05$ ); they also had significantly better health and well-being than those with hypertension combined with other chronic diseases (health: $m=47.0, p<0.001$; well-being: $m=65.1, p<0.001$ ); and those with other chronic diseases without hypertension (health: $m=47.4, p<0.001$; well-being: $m=65.2, p<0.001$ ). Respondents with hypertension alone had significantly better health $(p<0.01)$ and well-being $(p<0.05)$ than those with other chronic diseases combined with and without hypertension. There were no differences on health and well-being between the groups with other chronic diseases combined with and without hypertension $(p>0.05)$. These findings suggested that other chronic diseases, with and without hypertension, have more impact on health and well-being than hypertension alone.

\section{Discussion}

Overall findings on chronic disease were alarming, since $73 \%$ of respondents reported one or more chronic diseases. Although hypertension was the most frequently reported chronic condition, a substantial number of respondents reported the co-morbid conditions of diabetes mellitus and arthritis, similar to previous South African findings (Westaway et al., 1999). Given that the majority of respondents were pensioners, with a fixed income, and reliant on the public health sector for their treatment, no wonder that public health in South Africa is in a crisis (Westaway et al., 2003). This crisis is exacerbated by staff shortages and resources, particularly medication, patient overload and poor staff morale (Ijumba, 2002; Westaway et al., 2003). Moreover, chronic diseases are perceived as a lower priority in South African public health care, due to more acute and life-threatening HIV/AIDS infections. In addition, $73 \%$ of these respondents contribute to higher health care utilization and expenditure (Gijsen et al., 2001), and poor management of chronic diseases in the public health sector (Westaway et al., 2003), leading to poor health outcomes, such as disability and mortality (Gijsen et al., 2001).

Combining the hypertension only group with hypertension plus one or more other chronic diseases resulted in $50 \%$ of respondents suffering from hypertension: $57 \%$ of Indians, 52\% of coloreds, $50 \%$ of blacks and $49 \%$ of whites. These prevalence rates were considerably higher than the rates reported previously for these population groups (Steyn et al., 2001), and the 20-40\% reported for India (Reddy et al., 2005). As was found previously (Department of Health, 2001-2002), prevalence rates increased with age, but at a much more alarming rate. In comparison with $25 \%$ of men and $42 \%$ of women, aged 65 and older (Department of Health, 2001-2002), $78 \%$ of men and $76 \%$ of women aged 64 and older reported hypertension.

As was found in Sweden (Michelson et al., 2001), chronic disease status had more effect on the number of reported health problems than age. However, co-morbidity was associated with poor physical and mental health (Michelson et al., 2001; Oldridge et al., 2001; Ettinger et al., 1994). Indian respondents were most at risk for co-morbid hypertension, other chronic diseases and poor physical and mental health. Furthermore, $71 \%$ of these respondents were reliant on public health facilities for their treatment, suggesting that they experience considerable difficulties in managing their chronic conditions and co-morbidity (Westaway et al., 2003).

The first un-rotated factor accounted for $65.6 \%$ of the variance, higher than the 55\% reported in the US (McHorney et al., 1993). However, the high loadings for each of the 12 health and wellbeing items on the first alpha factor, ranging between 0.74 and 0.85 , were very similar to those of $0.67-0.82$ reported previously (McHorney et al., 1993). These findings reflected a common higher order physical and mental factor and provided support for construction of an overall health index. In addition, content validity was established through the Kaiser-Meyer-Olkin measure of item sampling adequacy.

In contrast with previous findings on the distinctness of physical and mental health (McHorney et al., 1993), rotation of the two physical and mental health factors resulted in one item (how much of the time has your physical health or emotional problems interfered with your social activities) loading on both factors. This item should load on both factors, because social functioning confounds physical and mental health by design (McHorney et al., 1993). However, in the US study (McHorney et al., 1993), this item loaded at 0.44 on the physical component and 0.71 on the mental 
component, in comparison with current findings of 0.57 (physical) and 0.52 (mental). Loadings on the other general health items ranged between 0.72 and 0.88 , comparable to the range of 0.68 and 0.88 found previously (McHorney et al., 1993). Loadings for the other five well-being items ranged between 0.77 and 0.89 , comparable to the range of 0.71 and 0.90 found previously (McHorney et al., 1993). Despite these slight differences, factorial analyses tended to confirm that the underlying dimensions of the SF-12 were general health and well-being for a US general sample and patients with chronic conditions (McHorney et al., 1993), and a multi-racial sample of South Africans in early and later old age.

Although the two factors were related, the correlation coefficient was significantly lower than the square root of the product of their reliability coefficients (Gaski and Nevin, 1985). This unique variance gave credibility to the distinctness of physical health and well-being and provided support for construct validity (Sitzia, 1999). The two factors had excellent reliability coefficients (Nunnally, 1978; Arias and de Vos, 1996; George and Mallery, 2003), similar to previous findings (Sherbourne and Stewart, 1991; Ware et al., 1996; Westaway and Maluka, 2004), and satisfied Sitzia's (1999) requirement for credible research.

Average scores on the health and well-being sub-scales were very similar to those reported previously for South African diabetic patients (Westaway, 2005) and in the US (Stewart et al., 1988). In contrast with previous research, which found that women and African-Americans tended to report poorer health and well-being (Stewart et al., 1988; Westaway et al., 1999), neither race, language, gender nor marital status affected health and wellbeing in the current study. These findings augur well for South Africa's multi-racial, multi-cultural and multi-ethnic population. Modest negative relationships were found between age, health and well-being. Most researchers find decrements in functioning and health due to age, but not well-being (Singer et al., 1999; Michelson et al., 2001; Alonso et al., 2004; Cesari et al., 2006; Fortin et al., 2006). To account for this remarkable stability, various authors have proposed a homeostatic principle of well-being or psychological adaptation that occurs with aging (Kempen et al., 1997; Singer et al., 1999; Cummins et al., 2004). An alternative explanation is that age is less important for health and well-being than multiple chronic conditions (Michelson et al., 2001). The current study provided support for this position as more important negative relationships were found between number of problems, health and well-being, indicative of the cumulative effects multiple problems on health and well-being.

The current study showed that the group with no chronic disease had better health and well-being than the other three groups. Mean scores on general health for this group were lower than those of 80.8 found in the Netherlands for no chronic disease, but virtually identical to those of 80.4 for well-being (Kempen et al., 1997). The group with hypertension alone also had better health and well-being than the groups with other chronic diseases combined with and without hypertension. Mean scores for this group were very similar to those reported for the Netherlands (Kempen et al., 1997) of 62.1 (general health) and 73.0 (wellbeing), providing support for the relationship between hypertension, co-morbidity, health and well-being (Fortin et al., 2006; Keles et al., 2007). Mean scores for the other two groups on health and well-being were remarkably similar. This may have been due undiagnosed hypertension (Steyn et al., 2001; Department of Health, 2001-2002), a common occurrence in South Africa. In this case, the mean scores on health and well-being for these two groups should be similar.

Overall findings tended to substantiate previous research on the affects of co-morbidity on health and well-being. These results indicated that primary health care providers should suspect concurring hypertension in their diagnosis of other chronic diseases. One service level response would be to examine all attendees at primary health care facilities for hypertension. Unfortunately, the crisis in the South African public health sector (Department of Health, 2001-2002), on which the majority of these respondents were reliant for their health care, means that this is an ideal rather than a real solution to the problem of hypertension. Acute shortages of staff and resources, patient overload and low staff morale in the public health sector (Westaway et al., 1999, 2003; Department of Health, 20012002; Ijumba, 2002), combined with the HIV/AIDS pandemic, has led to neglect of chronic diseases.

Yet, it has been shown that the risk factors (unhealthy diet, physical inactivity, alcohol consumption and smoking) for the four most important chronic conditions are modifiable (World Health Organization, 2002). The South African National Department of Health is to be congratulated on its stance regarding banning of smoking in public places. However, unhealthy diets, physical inactivity and alcohol consumption remain major challenges, particularly in the face of South African Breweries sponsorship of the recent Rugby World Cup. Control of chronic disease is a key issue in management (WHO, 2002), but previous South African research has shown poor management in South Africa's public health care sector (Steyn et al., 2001; Westaway et al., 2003). It is encouraging to see the recent announcement of a recruitment drive by the Department of Health to increase the number of staff in the public health sector, given that $64 \%$ of South Africa's population is totally dependent on the public health sector. However, increasing staff and resources without an improvement in effectiveness and equity means that the public health sector will continue to labor under the burden of second class health care.

Future research is required to ascertain whether: these results are replicable longitudinally, and with different samples of older South Africans; and whether chronic diseases, co-morbidity, health and well-being are affected by changes in policy and interventions, such as better co-ordination, integration and use of local resources for older South Africans.

\section{Conflict of interest statement}

None.

\section{Acknowledgements}

We wish to thank the respondents for participating in the study; the interviewers for their commitment to the respondents and the study; and Annie Swanepoel for data capture and cleaning. This study was funded by the Medical Research Council from baseline funds. 


\section{Appendix A}

Socio-Demographic Information

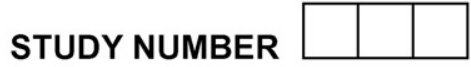

1. Age $\square$

3. Years of schooling

5. Home (preferred) language

$\begin{array}{ll}1=\text { Zulu } & 2=\text { Sotho } \\ 5=\text { Pedi } & 6=\text { Tswana } \\ 9=\text { Venda } & 10=\text { Ndebele }\end{array}$

2. Gender $1=$ Male $2=$ Female

4. Academic qualifications (degree, diploma)

$$
\begin{array}{ll}
1=\text { Diploma } & 2=\text { Degree } \\
3=\text { Certificate } & 4=\text { Other }
\end{array}
$$

$\begin{array}{ll}3=\text { Xhosa } & 4=\text { Tsonga } \\ 7=\text { Afrikaans } & 8=\text { English } \\ 11=\text { Swazi } & 12=\text { Other }\end{array}$

6. Marital status

1 = Single

$3=$ Widowed

$$
\begin{aligned}
& 2=\text { Married } \\
& 4=\text { Separated/divorced }
\end{aligned}
$$

7. Address

\section{General Health}

8. In general, would you say your health is:

\begin{tabular}{ccccc} 
Excellent & Very Good & Good & Fair & Poor \\
\hline 5 & 4.4 & 3.4 & 2 & \begin{tabular}{|l|l|}
1 \\
\hline
\end{tabular}
\end{tabular}

The following items are about activities you might do during a typical day. Does your health now limit you in these activities? If so, how much?

9. Moderate activities, such as moving a table, pushing a vacuum cleaner, bowling or playing golf

\begin{tabular}{lll} 
Yes & Yes & No, Not \\
Limited & $\begin{array}{l}\text { Limited } \\
\text { Limited }\end{array}$ & Lim \\
\hline 0 & A Little & At all \\
\hline 1 & 2 \\
\hline 0 & 1 & 2 \\
\hline
\end{tabular}

10. Climbing several flights of stairs

During the past 4 weeks, have you had any of the following problems with your work or other regular daily activities as a result of your physical health?

11. Accomplished less than you would like

Yes No

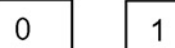

12. Were limited in the kind of work or other activities

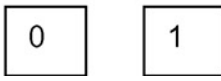


13. During the past $\mathbf{4}$ weeks, how much did pain interfere with your normal work (including both work outside the home and housework)?

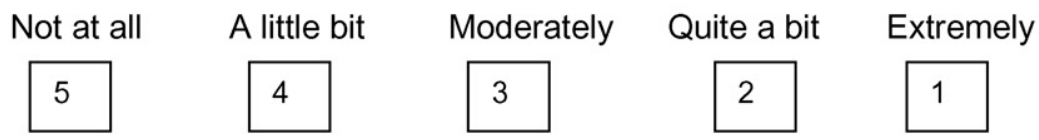

\section{Well-Being}

During the past $\mathbf{4}$ weeks, have you had any of the following problems with your work or other regular daily activities as a result of any emotional problems (such as feeling depressed or anxious)?

14. Accomplished less than you would like

Yes No
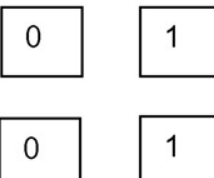

These questions are about how you feel and how things have been with you during the past $\mathbf{4}$ weeks. For each question, please give the one answer that comes closest to the way you have been feeling. How much of the time during the past $\mathbf{4}$ weeks.

16. Have you felt calm and peaceful?

17. Did you have a lot of energy?

18. Have you felt downhearted and blue?

\begin{tabular}{|c|c|c|c|c|c|}
\hline $\begin{array}{l}\text { All } \\
\text { Of the } \\
\text { Time }\end{array}$ & $\begin{array}{l}\text { Most } \\
\text { Of the }\end{array}$ & $\begin{array}{l}\text { A Good } \\
\text { Bit of }\end{array}$ & $\begin{array}{l}\text { Some } \\
\text { Of the }\end{array}$ & $\begin{array}{l}\text { A Little } \\
\text { Of the }\end{array}$ & $\begin{array}{l}\text { None } \\
\text { Of the } \\
\text { Time }\end{array}$ \\
\hline 6 & 5 & 4 & 3 & 2 & 1 \\
\hline 6 & 5 & 4 & 3 & 2 & 1 \\
\hline 1 & 2 & 3 & 4 & 5 & 6 \\
\hline
\end{tabular}

19. During the past $\mathbf{4}$ weeks, how much of the time has your physical health or emotional problems interfered with your social activities (like visiting with friends, relatives, etc.)?

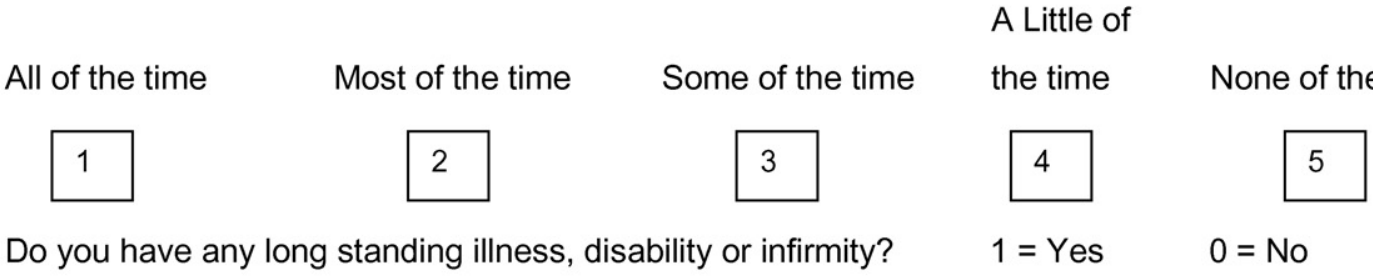

20. Do you have any long standing illness, disability or infirmity? $\quad 1=$ Yes $\quad 0=$ No

21. If yes, what is it?

22. Have you had any of the following problems over the last 4 weeks

Sleep problems

Concentration difficulties

Nervous problems

Worrying over every little thing

Always tired

Headaches

Constipation

Fainting/dizziness

Sickness/nausea

\begin{tabular}{|c|c|c|}
\hline $\mathbf{Y}$ & $\mathbf{N}$ & \\
\hline 1 & 0 & Palpitations (heart beating rapidly) \\
\hline 1 & 0 & Back trouble \\
\hline 1 & 0 & Persistent cough \\
\hline 1 & 0 & Colds/flu \\
\hline 1 & 0 & Bladder/kidney problems \\
\hline 1 & 0 & Stiff/painful joints \\
\hline 1 & 0 & Sinus/catarrh/blocked nose \\
\hline 1 & 0 & Trouble with eyes \\
\hline 1 & 0 & Trouble with ears \\
\hline
\end{tabular}

\begin{tabular}{|l|l|}
\multicolumn{1}{c}{$\mathbf{Y}$} & $\mathbf{N}$ \\
\hline 1 & 0 \\
\hline 1 & 0 \\
\hline 1 & 0 \\
\hline 1 & 0 \\
\hline 1 & 0 \\
\hline 1 & 0 \\
\hline 1 & 0 \\
\hline 1 & 0 \\
\hline 1 & 0 \\
\hline
\end{tabular}




\section{References}

Alonso, J., Ferrer, M., Gandek, B., Ware, J.E., Aaronson, N.K., Mosconi, P., Rasmussen, N.K., Bullinger, M., Fukuhara, S., Kaasa, S., Leplège, A., the IQOLA Project Group, 2004. Health-related quality of life associated with chronic conditions in eight countries: results from the International Quality of Life Assessment (IQOLA) Project. Qual. Life Res. 13, 283-298.

Arias, E., de Vos, S., 1996. Using housing items to indicate socioeconomic status: Latin America. Soc. Indic. Res. 38, 53-80.

Bradshaw, D., Groenewald, P., Laubscher, R., Nannan, N., Nojilana, B., Norman, R. Pieterse, D., Schneider, M., Bourne, D.E., Timaeus, I.M., Dorrington, R., Johnson, L., 2003. Initial burden of disease estimates for South Africa, 2000. S. Afr. Med. J. 93, 682-688.

Cesari, M. Onder, G., Russo, A Zamboni, V., Barillaro, C, Ferrucci, L, Pahor, M. Bernabei, R., Landi, F., 2006. Comorbidity and physical function: results from the aging and longevity study in the Sirente geographic area (ilSIRENTE Study). Gerontology 52, 24-32.

Child, D., 1970. The Essentials of Factor Analysis. Holt, Rinehart \& Winston, London.

Cronbach, L.J., 1970. Essentials of Psychological Testing, Third ed. Harper \& Row, New York.

Cummins, R.A., Lau, A.L.D., Stokes, M., 2004. HRQOL and subjective well-being: noncomplementary forms of outcome measurement. Expert Rev. Pharmacoeconomics Outcomes Res. 4, 413-420

Department of Health, 2001-2002. South Africa Demographic and Health Survey 1998. National Department of Health, Pretoria, ISBN No: 0-621-31456-X.

Ettinger, W.H., Davis, M.A., Neuhas, J.M., Mallon, K.P., 1994. Long-term physical functioning in persons with knee osteoarthritis from NHANES I: effects of comorbid medical conditions. J. Clin. Epidemiol. 47, 809-815.

Fortin, M., Bravo, G., Hudon, C., Lapointe, L., Almirall, J., Dubois, M.-F., Vanasse, A., 2006. Relationship between multimorbidity and health-related quality of life of patients in primary care. Qual. Life Res. 15, 83-91.

Gaski, J.F., Nevin, J.R., 1985. The differential effects of exercised and unexercised power sources in a marketing channel. J. Market Res. 22, 130-142.

George, D., Mallery, P., 2003. SPSS for Windows Step by Step: A Simple Guide and Reference, 11.0 Update, Fourth ed. Allyn \& Bacon, Boston.

Gijsen, R., Hoeymans, N., Schellevis, F.G., Ruwaard, D., Satariano, W.A., van den Bos, G.A.M., 2001. Causes and consequences of comorbidity: a review. J. Clin. Epidemiol. 54, 661-674.

Ijumba, P., 2002. Voices of primary health care facility workers. In: Ijumba, P., Ntuli, A., Barron, P. (Eds.), South African Health Review 2002. Health Systems Trust, Durban, pp. 181-200.

Joubert, J., Bradshaw, D., 2004. Health of older persons. In: Ijumba, P., Day, C., Ntuli, A. (Eds.), South African Health Review 2003/4. Health Systems Trust, Durban, pp. 147-162.

Kaiser, H.F., 1974. An index of factorial simplicity. Psychometrika 39, 31-36.

Keles, H., Ekici, A., Ekici, M., Bulcun, E., Altinkaya, V., 2007. Effect of chronic diseases and associated psychological distress on health-related quality of life. Intern. Med. J. 37, 6-11.

Kempen, G.I.J.M., Ormel, J., Brilman, E.I., Relyveld, J., 1997. Adaptive responses among Dutch elderly: the impact of eight chronic medical conditions on healthrelated quality of life. Am. J. Pub. Health 87, 38-44.

Kim, J., Mueller, C.W., 1978. Factor Analysis: Statistical Methods and Practica Issues. Series: Quantitative Applications in the Social Sciences. Sage Publications, Newbury Park.

Lehohla, P., 2006. Stats in Brief, 2006. Statistics South Africa, Pretoria.

Macintyre, S., Hunt, K., Sweeting, H., 1996. Gender differences in health: are things really as simple as they seem? Soc. Sci. Med. 42, 617-624.

Macran, S., Clarke, L., Joshi, H., 1996. Women's health: dimensions and differentials. Soc. Sci. Med. 42, 1203-1216.

May, J., 2002. Chronic poverty and older people in South Africa. Chronic Poverty Research Centre Working Paper 25. Available from: http://www.chronicpoverty.org/pdfs/Jmay.pdf [Accessed 10 May 2005].
McHorney, C.A., Ware, J.E., Raczek, A.E., 1993. The MOS 36-item short-form health survey (SF-36). II. Psychometric and clinical tests of validity in measuring physical and mental health constructs. Med. Care 31, 247-263.

Michelson, H., Bolund, C., Brandberg, Y., 2001. Multiple chronic health problems are negatively associated with health related quality of life (HRQoL) irrespective of age. Qual. Life Res. 9, 1093-1104.

Nunnally, J.C., 1978. Psychometric Theory, Second ed. McGraw-Hill, New York.

Oldridge, N.B., Stump, T.E., Nothwehr, F.K., Clark, D.O., 2001. Prevalence and outcomes of comorbid metabolic and cardiovascular conditions in middle- and older-age adults. J. Clin. Epidemiol. 54, 928-934.

Reddy, K.S., Shah, B., Varghese, C., Ramadoss, A., 2005. Responding to the threat of chronic diseases in India. Lancet 366, 1746-1751.

Sherbourne, C.D., Stewart, A.L., 1991. The MOS social support survey. Soc. Sci. Med. 32, 705-714.

Singer, M.A., Hopman, W.M., MacKenzie, T.A., 1999. Physical functioning and mental health in patients with chronic medical conditions. Qual. Life Res. 8, 687-691.

Sitzia, J., 1999. How valid and reliable are patient satisfaction data? An analysis of 195 studies. Int. J. Qual. Health Care 11, 319-328.

Stewart, A.L., Hays, R.D., Ware, J.E., 1988. The MOS short-form general health survey: reliability and validity in a patient population. Med. Care 26, 724735.

Stewart, A.L., Greenfield, S., Hays, R.D., Wells, K., Rogers, W.H., Berry, S.D., McGlynn, E.A., Ware, J.E., 1989. Functional status and well-being of patients with chronic conditions: results from the medical outcomes study. J. Am. Med. Assoc. 262, 907-913.

Steyn, K., Gaziano, T.A., Bradshaw, D., Laubscher, R., Fourie, J., 2001. Hypertension in South African adults: results from the Demographic and Health Survey, 1998. J. Hypertens. 19, 1717-1725.

Strong, K., Mathers, C., Leeder, S., Beaglehole, R., 2005. Preventing chronic diseases: how many lives can we save? Lancet 366, 1578-1582.

Wang, L., Kong, L., Wu, F., Bai, Y., Burton, R., 2005. Preventing chronic diseases in China. Lancet 366, 1821-1824.

Ware, J.E., Kosinski, M., Keller, S.D., 1996. A 12-item short form health survey: construction of scales and preliminary tests of reliability and validity. Med. Care $34,220-233$.

Westaway, M.S., 2005. The effects of social support on health, well-being and management of diabetes mellitus: a black South African perspective. Ethnicity Health 10, 73-89.

Westaway, M.S., 2006. A longitudinal investigation of satisfaction with personal and environmental quality of life in an informal South African housing settlement, Doornkop, Soweto. Habitat Int. 30, 175-189.

Westaway, M.S., 2007. Life and neighborhood satisfaction of black and white residents in a middle-class suburb of Johannesburg. Psychol. Rep. 100, 489494.

Westaway, M.S., Gumede, T., 2001. Satisfaction with personal and environmental quality of life: a black South African informal settlement perspective. Curationis $24,28-34$.

Westaway, M.S., Maluka, C.S., 2004. Impact of chronic diseases on the health-related quality of life of South Africans. S. Afr. Med. J. 94, 937.

Westaway, M.S., Viljoen, E., Rheeder, P., 1999. Does blood glucose control affect the health-related quality of life (HRQOL) of urban black South African type 2 diabetes mellitus patients? Diabetes Res. 34, 209-217.

Westaway, M.S., Seager, J.R., van Zyl, D.G., Oosthuizen, H., 2003. Management of diabetes mellitus in outpatient facilities is achieving poor results. S. Afr. Med. J. 93,846 .

Westaway, M.S., Olorunju, S.A.S., Rai, L.J., 2007. Which personal quality of life domains affect the happiness of older South Africans? Qual. Life Res. 16, 1425-1438.

World Health Report, 2002. Reducing Risks, Promoting Healthy Life. World Health Organization, Geneva. 